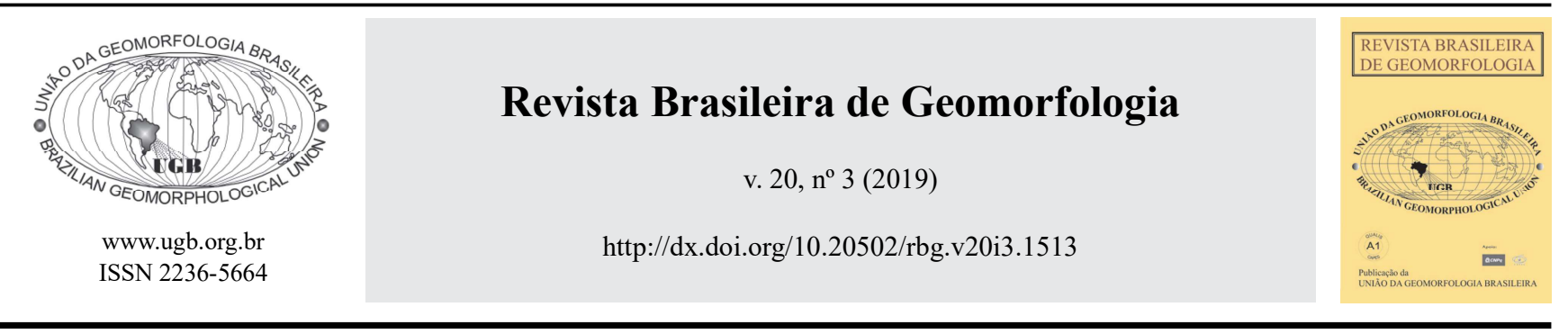

\title{
DISTRIBUIÇÃO E CONTEXTO GEOLÓGICO-GEOMORFOLÓGICO DA BAUXITA NA REGIÃO DE ESPERA FELIZ, SUL DA SERRA DO CAPARAÓ, MG/ES
}

\author{
DISTRIBUTION AND GEOLOGICAL-GEOMORPHOLOGICAL \\ CONTEXT OF BAUXITE IN THE ESPERA FELIZ REGION, SOUTH OF \\ CAPARAÓ MOUNTAIN, MG / ES
}

\author{
Fabrício Sousa da Silva \\ Departamento de Geografia, Universidade Federal de Minas Gerais \\ Av. Antônio Carlos, 6627, Belo Horizonte, Minas Gerais. CEP:31.270-901. Brasil \\ ORCID: 0000-0001-6895-6496 \\ E-mail:fabriciosousasilv@gmail.com
}

Fábio Soares de Oliveira

Departamento de Geografia, Universidade Federal de Minas Gerais Av. Antônio Carlos, 6627, Belo Horizonte, Minas Gerais. CEP:31.270-901. Brasil ORCID: 0000-0002-1450-7609

E-mail:fabiosolos@gmail.com

Carlos Roberto Souza Filho

Instituto de Geociências, Universidade Estadual de Campinas Rua João Pandiá Calógeras, 51, Campinas. São Paulo. CEP: 13.083-876. Brasil

ORCID: 0000-0001-5366-3439

E-mail: beto@ige.unicamp.br

\section{Informações sobre o Artigo}

Recebido (Received): 08/09/2018

Aceito (Accepted):

$16 / 04 / 2019$

Palavras-chave:

Bauxita; Prospecção Mineral; Sensoriamento Remoto; Intemperismo.

\section{Keywords:}

Bauxite; Mineral Prospecting; Remote Sensing.

\section{Resumo:}

Este estudo objetivou identificar e caracterizar o contexto geológicogeomorfólogico das ocorrências de bauxita no sul da Serra do Caparaó, na divisa entre Minas Gerais e Espírito Santo, utilizando de dados de espectroscopia de reflectância, difração de raios-X e imagens multiespectrais do sensor Aster. A difração de raios- $X$ evidenciou a presença de gibbsita, caulinita, hematita, goethita e quartzo na bauxita. Espécies minerais equivalentes também foram determinadas a partir da interpretação espectro-mineralógica. A reflectância espectral demonstrou a existência de um nível de degradação diferenciado entre as amostras. A degradação sugere a transformação das condições ambientais (sobretudo bioclimáticas). Foram utilizadas cinco assinaturas espectrais obtidas em laboratório a partir de amostras de bauxita para classificação espectral da imagem ASTER com o classificador Spectral Angler Mapper (SAM). Os resultados mostram a distribuição da bauxita em todos os compartimentos geológicos da região. Trabalhos de campo, entretanto, indicam a existência de inconsistências e falsos-positivos. A principal inconsistência está relacionada à 
presença de bauxita associada aos paragnaisses do Grupo Andrelândia, que sugere não ter sido a principal rocha formadora de bauxita. A maior parte das ocorrências está ligada às rochas da Suíte Caparaó e em posições da paisagem que reiteram a existência de uma paleo-superfície bauxitizada, desnivelada topograficamente.

\begin{abstract}
:
This paper aimed to identify and characterize the geological-geomorphological context of bauxite occurrences in the south of Caparaó Mountain, between Minas Gerais and Espírito Santo states, using data from reflectance spectroscopy, X-ray diffraction and multispectral images of the sensor Aster. X-ray diffraction evidenced the presence of gibbsite, kaolinite, hematite, goethite and quartz in bauxite. Equivalent mineral species were also determined from spectral-mineralogical interpretation. The spectral reflectance demonstrated the existence of a differentiated level of degradation between the samples. Degradation suggests the transformation of environmental conditions (mainly bioclimatic). Five spectral signatures obtained in the laboratory from bauxite samples were used for spectral classification of the ASTER image with the Spectral Angler Mapper (SAM) classifier. The results show the distribution of bauxite in all the geological compartments of the region. Fieldwork, however, indicates the existence of inconsistencies and false positives. The main inconsistency is related to the presence of bauxite associated with the paragneisses of the Andrelândia Group, which suggests that it was not the main bauxite rock-forming. Most of the occurrences are linked to the rocks of the Caparaó Suite and in landscape positions that reiterate the existence of a paleo-surface bauxitized, topographically uneven.
\end{abstract}

\section{Introdução}

A bauxita é um produto do intemperismo intenso sobre rochas e sedimentos na superfície terrestre (BIGARELLA et al., 2007). Desde seu descobrimento na região de Le Baux, França (CARVALHO, 1989), ela vem sendo utilizada como fonte de alumínio. Essa fonte se justifica pela presença majoritária da gibbsita na sua constituição, podendo ocorrer também argilominerais, óxidos e hidróxidos de ferro, óxidos de titânio e quartzo (VARAJÃO \& MENEZES, 1988).

As regiões tropicais apresentam as condições ambientais necessárias à formação da bauxita (BARDOSSY \& ALEVA, 1990; TARDY et al., 1991; TARDY, 1993), como elevada temperatura e umidade em quantidade e intensidade suficientes para promover $\mathrm{o}$ intemperismo das rochas. Quando presente em regiões de climas temperado ou desértico, a bauxita representa o produto de um contexto climático pretérito, preservada na paisagem como um componente paleoambiental (BARDOSSY, 1981). Assim, além do interesse econômico, a bauxita é um importante indicador de evolução da paisagem.

Embora sejam muitas as etapas envolvidas na caracterização de um depósito bauxítico, como o reconhecimento de sua gênese, dimensão e possibilidades de uso, nenhuma delas precede a descoberta e localização do depósito. A descoberta de ocorrências é, a priori, resultado das atividades de pesquisa mineral através de trabalhos de campo, geralmente muito exaustivos e com elevado custo de operação. Como se trata de uma etapa inicial e da qual depende a continuidade dos investimentos, seus resultados terão efeitos em todas as etapas subsequentes.

Objetivando otimizar a descoberta de possíveis reservas minerais sem onerar o processo de investigação, diversos estudiosos vêm se dedicando ao emprego das Geotecnologias na identificação e localização de potenciais ocorrências. Ferramentas de caráter tecnológico, como o sensoriamento remoto, ganharam destaque para esse fim, basicamente porque permitem incorporar escalas regionais e porque melhoram o tempo de resposta entre a pesquisa e a possibilidade de tomada de decisão. Rocha e Souza Filho (2013) e Souza Filho e Crósta (2003), por exemplo, demonstraram o potencial do sensoriamento remoto, em especial da espectroscopia, na identificação mineralógica de formações superficiais. Os autores concluíram que se trata de uma ferramenta com boa relação custo-benefício, uma vez que os dados obtidos remotamente por sensores multiespectrais, como o Landsat e o ASTER, ofereceram resultados satisfatórios. No mesmo sentido, Ducart et al. (2006) e Vicente e Souza Filho (2011) expõem que o sensoriamento remoto é passível de ser utilizado na identificação mineralógica porque os minerais presentes nas coberturas superficiais exibem bandas de absorção bem definidas no visível, infravermelho próximo (Visible/NearInfrared - VNIR) 
(goethita e hematita) e no infravermelho de ondas curtas (ShortwaveInfrared - SWIR) (caulinita e gibbsita), permitindo a discriminação de paragêneses mineralógicas.

Dentre os benefícios oferecidos pelo sensoriamento na identificação de depósitos bauxíticos está a possibilidade de verificar ocorrências em áreas cujos depósitos encontram-se isolados uns dos outros, representando coberturas residuais e, por isso, com distribuição difícil de ser compreendida apenas por estudos de campo. Neste contexto se insere a região sudeste de Minas Gerais, onde ocorre um cinturão aluminoso orientado sentido NE-SW, no qual as principais ocorrências de bauxita são conhecidas nos municípios de Cataguases, Miraí, Descoberto e Itamarati de Minas. Estudos realizados neste cinturão destacaram a presença de depósitos de bauxita em cotas variando de 700 a 900 metros de altitude (LOPES, 1987; 1989), enfatizando sua localização pontual e compartimentada (ROMANO \& CASTAÑEDA, 2006). Na região de Espera Feliz, em específico, os depósitos são pouco conhecidos. Apenas uma das ocorrências nessa região teve sua gênese detalhada por Soares (2013), que revelou se tratar de um produto da alteração de um gnaisse de fácies granulito, especificamente um charno-enderbito. Posteriormente, Mateus et al. $(2016$; 2017) evidenciaram as relações pedogeomorfológicas entre a presença da bauxita e de cicatrizes de movimentos de massa, bem como da relação genética entre a bauxita e do solo sobreposto através do processo de ressilicificação.

Considerando a contribuição que o sensoriamento remoto pode trazer para o conhecimento de depósitos bauxíticos e avaliando a importância da prospecção de novas ocorrências, este estudo teve como objetivo avaliar a distribuição da bauxita na região de Espera Feliz a partir da espacialização das ocorrências e do contexto geológico-geomorfológico em que ocorrem.

\section{Materiais e métodos}

\section{1 Área de Estudo}

A região de Espera Feliz compreende um quadrante limitado pelas coordenadas 7727970 N 186950 O e 7708970 N 212450 O, envolvendo um conjunto de municípios inseridos na divisa entre os estados de Minas Gerais e Espírito Santo, próximo à Serra do Caparaó (Figura 1).

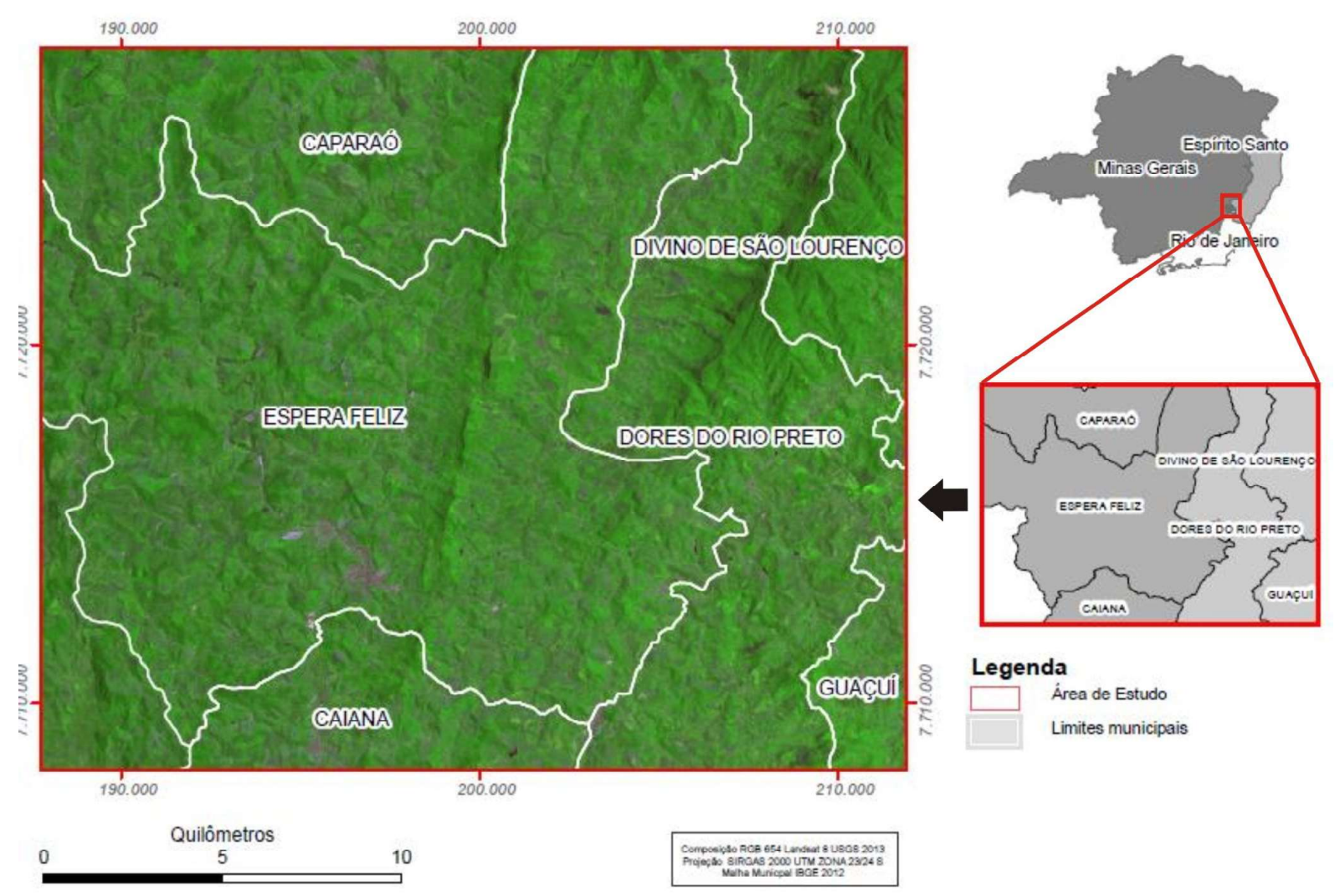

Figura 1 - Localização da área de estudo, denominada Região de Espera Feliz (MG/ES), delimitada pelo quadrante vermelho. 
O relevo na área de estudo possui forte controle litoestrutural. Observam-se serras com espigões alongados segundo a foliação principal NNE-SSW. Na Serra do Caparaó as elevações superam $2800 \mathrm{~m}$, sendo bordejada por terrenos com cotas entre 600 e $1100 \mathrm{~m}$. Nesse intervalo, morros ondulados a suavemente ondulados são separados entre si por vales planos preenchidos por sedimentos. O substrato rochoso é composto em grande parte por gnaisses e granitos pré-cambrianos do Complexo Juiz de Fora, mais especificamente da Suíte Caparaó e do Grupo Andrelândia (HORN et al., 2007), além do Gnaisse Tonalítico Manhuaçu. Ocorrem Latossolos Vermelho-Amarelos nos morros e Cambissolos Háplicos e Neossolos Litólicos nas vertentes mais íngremes. Nas baixadas, predominam Gleissolos e Neossolos Flúvicos (RODRIGUES, 2011). Sobre a cobertura vegetal, alguns remanescentes de floresta ombrófila densa estão presentes no entorno do Parque Nacional do Caparaó, embora grande parte tenha sido desmatada para o plantio de café, que predomina na paisagem. Nas partes altas do Parque ocorrem campos de altitude.

\subsection{Procedimentos Metodológicos}

Os procedimentos iniciais envolveram a realização de pesquisa bibliográfica e levantamento dos produtos cartográficos digitais disponíveis para a área de estudo. Esses produtos compreendem: i) mapa geológico da Folha Espera Feliz (SF 24-V-A-IV) da CPRM, na escala de 1:100.000, acompanhada de relatório; ii) projeto SIG geológico, na escala de 1:50.000, disponibilizado no Geobank da CPRM; e iii) imagem multiespectral do sensor ASTER (Advanced Spaceborne Thermal Emission and Reflection Radiometer) (órbita 216; ponto 74) datada de 15/04/2008. O sensor ASTER integra o Earth Observing System (EOS-NASA) e está vinculado ao satélite TERRA, com três sistemas independentes que captam dados em 14 bandas espectrais: 3 nas faixas do visível (VIS - visible) ao infravermelho próximo (NIR - near infrared) com resolução espacial de $15 \mathrm{~m}$, 6 bandas no infravermelho de ondas curtas (SWIR shortwave infrared) na resolução de $30 \mathrm{~m}$ e 5 bandas na região do infravermelho termal (TIR - thermal infrared) com resolução de $90 \mathrm{~m}$ (Abrams, 2000). As cenas ASTER cobrem uma área de aproximadamente $60 \mathrm{x}$ $60 \mathrm{~km}$. Com o sistema VIS-NIR do ASTER é possível gerar pares estereoscópicos em comprimentos de onda do NIR, já que o mesmo possui dois telescópios, dos quais um opera com retrovisada ao longo da órbita do satélite. A escolha do sensor ASTER se deve ao fato de que numerosos estudos, como Vicente \& Souza Filho, (2011), indicam a possibilidade de detecção de minerais comumente associados a bauxita, como gibbsita e argilominerais, a partir das bandas SWIR desse sensor.

Os trabalhos de campo foram dirigidos para a coleta de amostras de bauxita e caracterização da geomorfologia e pedologia local. Segundo Nahon e Tardy (1992), as fácies de alteração da bauxita mais próxima à superfície e, consequentemente, passível de detecção por sensores orbitais, é a bauxita fragmentada, situada logo abaixo de uma camada de material pedogeneizado, o sólum. Assim sendo, amostras de bauxita fragmentada foram coletadas numa profundidade média de 1,5 metros nas cinco principais ocorrências conhecidas na região (Figura 2).

As amostras coletadas foram caracterizadas do ponto de vista espectral e mineralógico. A caracterização espectral foi realizada por meio do espectrorradiômetro FieldSpec High-Resolution (Analytical Spectral Devices), que forneceu a assinatura espectral no intervalo de $350 \mathrm{~nm}$ a $2500 \mathrm{~nm}$. Os padrões de absorção dos minerais observados foram comparados com aqueles reportados pela literatura (CLARK et al., 1993). Após a obtenção dessas curvas de referência, foi realizada uma correção da reflectância absoluta através da média entre espectros de uma mesma amostra, considerando que cada amostra foi lida três vezes no espectrorradiômetro. Também foi realizada a remoção do contínuo interativo para uma melhor análise espectral. Tanto a média quanto a remoção foram realizadas no algoritmo PRISM. Em seguida, as curvas espectrais finais foram exportadas para o formato Lib e, posteriormente, reamostradas no Software ENVI, sendo utilizadas na classificação supervisionada.

A caracterização mineralógica foi realizada com o objetivo de auxiliar a identificação de quais seriam os minerais presentes na bauxita e, por isso, responsáveis pelas curvas de reflectância obtidas. A análise foi feita no Laboratório de Difração de Raios-X do Departamento de Geologia da Universidade Federal de Ouro Preto. Amostras pulverizadas em moinho de disco orbital foram dispostas em suportes apropriados e levadas ao Difratômetro Empyrian da Panalytical com radiação de $\mathrm{CuK} \alpha$, entre $2 \mathrm{a} 70^{\circ} 2 \theta$ utilizando a fração pó total, com passo de leitura de $0,6^{\circ} / \mathrm{min}$. Os difratogramas foram interpretados através do software X'Pert High Score Plus e através de padrões da literatura (BRINDLEY \& BROWN, 1980). 


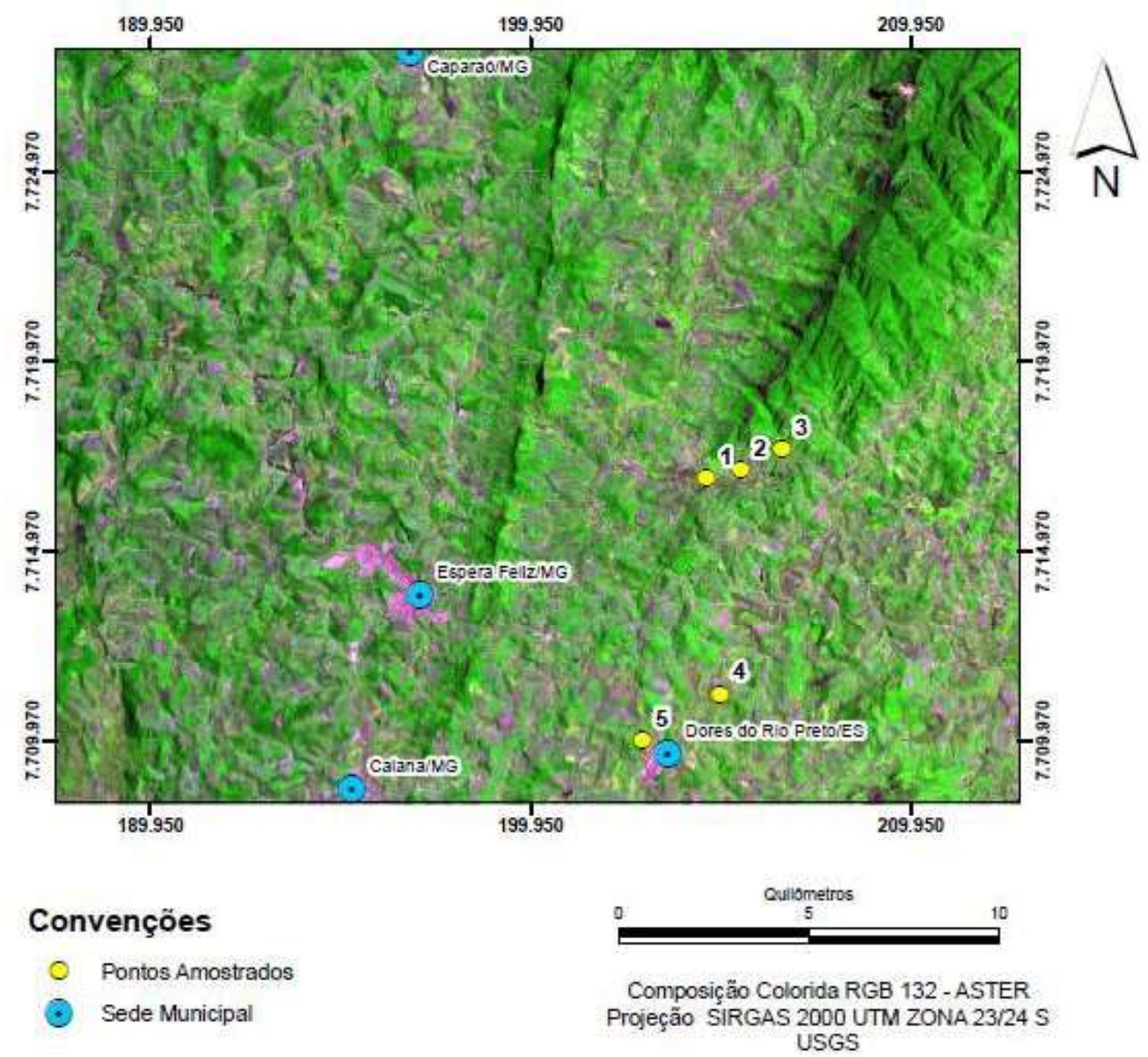

Figura 2 - Localização dos pontos amostrados dentro da área de estudo.

Uma vez obtidas as curvas espectrais e identificados os minerais responsáveis por elas, foi realizada a classificação supervisionada da imagem conforme a metodologia proposta por Rocha e Souza Filho (2013) e Menezes e Almeida (2011). Foi realizada, inicialmente, o pré-processamento da imagem. Esta etapa incluiu a correção geométrica a partir de uma imagem Landsat OLI-8, correspondente e previamente registrada, visando remover os deslocamentos da imagem em relação à situação real, ocasionados pelos movimentos de rotação da Terra. Em seguida, a imagem foi calibrada radiometricamente para compensar erros radiométricos, defeitos do sensor ou variações no ângulo de leitura e ruído do sistema produtor da imagem. Por fim, foi realizada a homogeneização dos tamanhos dos pixels da imagem, a fim de utilizar em todas as 9 bandas uma resolução espacial de $15 \mathrm{~m}$, garantindo boa informação espectral e espacial. A homogeneização dos pixels foi realizada através do módulo FLAASH do ENVI, seguindo o roteiro de conversão proposto por Santos (2009).
Depois de concluídas as etapas de pré-processamento da imagem, foi realizada uma classificação supervisionada no ENVI, utilizando a biblioteca criada, com auxilio do algoritmo classificador SAM (Spectral Angler Mapper). No classificador SAM, quanto menor for o ângulo entre a referência (biblioteca) e o pixel da imagem, maior será a acurácia da biblioteca, melhorando os resultados encontrados. Nessa etapa, foram realizadas classificações independentes, ou seja, foi identificado um alvo tipo (como por exemplo, fragmentos de bauxita) em cada classificação com "ângulo limiar teste". Para tal, foram testados diferentes limiares, definidos por ângulos de radianos, que no caso dos fragmentos de bauxita variaram de 0.19 a 0.25 . Esses ângulos foram inseridos no classificador de modo que todas as possibilidades de classificação fossem contempladas, ou seja, abaixo do limiar mínimo para cada alvo tipo nenhum alvo foi identificado e, acima dos limiares máximos, houve uma grande confusão na classificação.

Uma vez obtida a classificação da imagem, 
expondo pontos de possíveis ocorrências de bauxita, foi realizado um segundo trabalho de campo para validação. Esse campo consistiu na visita aos principais pontos identificados para verificação da presença de bauxita no perfil laterítico ou não. Essa verificação se deu tanto em cortes de estradas e exposições em cascalheiras, quanto por tradagem até o limite de $1,5 \mathrm{~m}$ de profundidade. Os materiais encontrados foram descritos e fotografados.

A partir da classificação já validada, as bauxitas confirmadas foram relacionadas com seu contexto geológico e geomorfológico. O contexto geológico considerou os principais litotipos presentes na respectiva formação geológica, ao passo que o contexto geomorfológico considerou aspectos relacionados à cota altimétrica, declividade e posição na vertente, quais sejam topo de morro, encosta ou sopé (Ruhe, 1975).

\section{Resultados e Discussões}

3.1 Caracterização mineralógica e espectroscópica dos materiais coletados

A análise mineralógica (Figura 3) revelou a presença majoritária de gibbsita em todas as bauxitas amostradas, corroborando as observações de Soares et al. (2014). A intensidade dos picos de gibbsita permite inferir a existência de dois grupos: i) grupo G1, constituído pelos fragmentos de bauxita localizados ao norte da área de estudo (pontos 1, 2 e 3), com intensidade de detecção inferior a quatro mil pontos de contagem e, ii) grupo G2, constituído pelas amostras 4 e 5, localizados a sul, onde todos os fragmentos amostrados apresentaram intensidade de detecção da gibbsita superior a dez mil pontos de contagem. Embora a intensidade dos picos não possa ser utilizada como um reflexo quantitativo direto, ela diz muito sobre a abundância do mineral no material analisado.

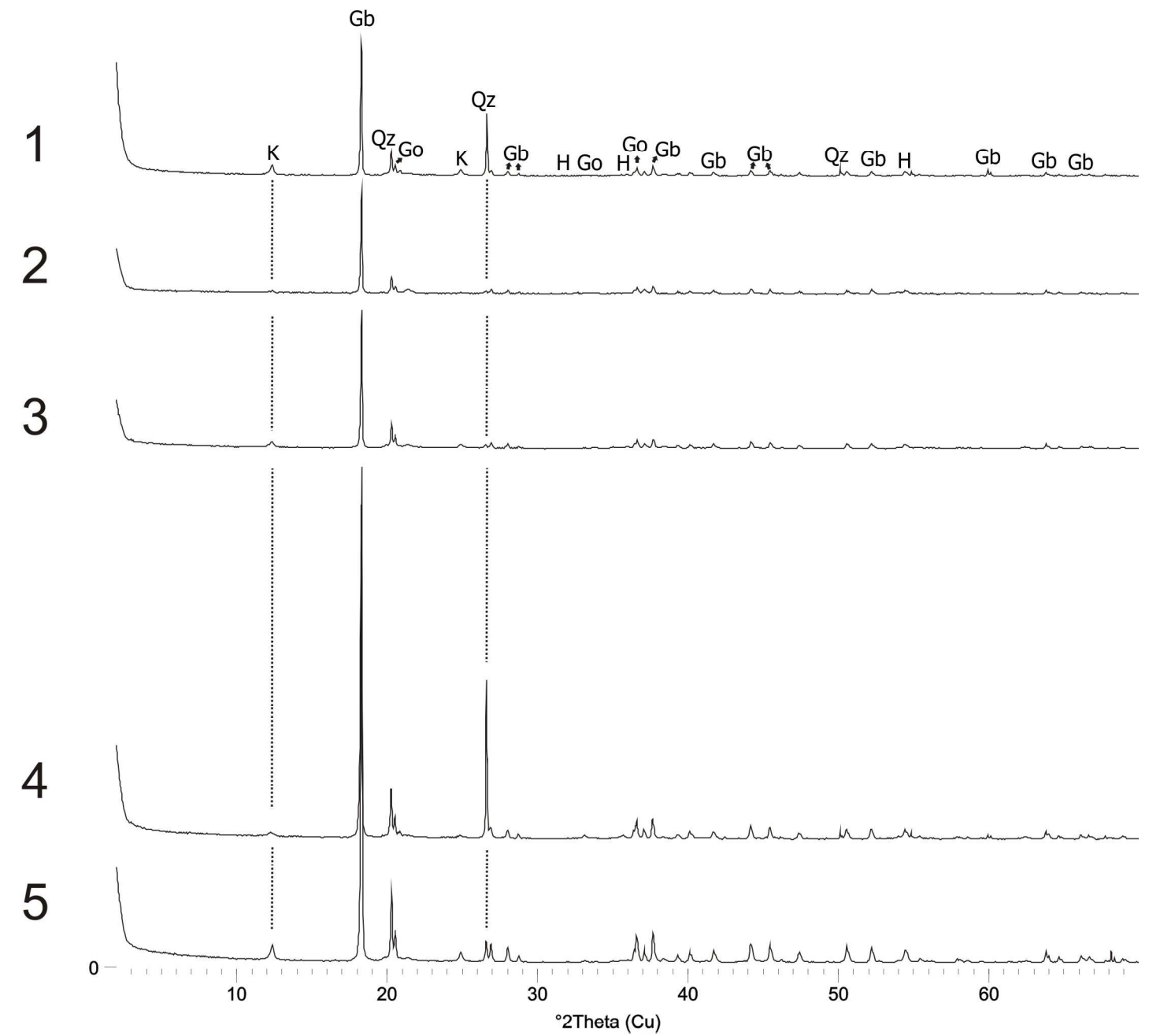

Figura 3 - Difratogramas (radiação de Cu) representativos dos fragmentos de bauxita coletados nos pontos de 1 a 5. $K=$ caulinita; Gb= gibbsita; $Q z=$ quartzo; Go = goethita e $H$ = hematita. 
Além da gibbsita, foram identificados outros minerais que são igualmente comuns na bauxita: caulinita, goethita, hematita e quartzo. A intensidade dos picos de quartzo variou dentro dos próprios grupos. No G1 apenas o ponto 1 apresentou detecção do quartzo no seu pico de maior difração $(\mathrm{d} \sim 3,34)$, ao passo que no $\mathrm{G} 2$ todos os fragmentos apresentaram picos bem definidos e com intensidade moderada. Para a caulinita, a intensidade de todos os pontos amostrados é baixa e os picos possuem a base alargada, não sendo geometricamente perfeitos. Em G2 alguns fragmentos não apresentaram o pico de maior difração da caulinita $(\mathrm{d} \sim 7,2)$.

Diversos estudos reportam os motivos que levam a uma diferenciação mineralógica nas bauxitas (HOSE, 1960; VALENTON, 1974; CARVALHO, 1989; BARDOSSY E ALEVA, 1990; MELFI, 1997; BIGARELLA et al., 2007). Em primeiro lugar, é preciso considerar a mineralogia do material de origem. O quartzo, por exemplo, é um mineral resistente e permanece mesmo em condições de forte intemperismo (GOLDISH, 1938). Assim, caso o material de origem seja rico em quartzo, se não houver sua remoção mecânica, ele tende a acumular no manto de alteração. Além disso, existem variações composicionais e texturais nas rochas que podem justificar o fato do quartzo estar concentrado em bandas ou zoneamentos específicos, não se distribuindo equitativamente. Nesse caso, os produtos de alteração poderão conter mais ou menos desse mineral, considerando sua litodependência.

No caso da caulinita, há mais de uma origem possível para o mineral (VARAJÃO et al., 2001). Em algumas bauxitas, a caulinita está presente como residual daquela ainda não transformada em gibbsita. Nesse caso, a transformação do mineral primário seria inicialmente em caulinita e a caulinita seria intemperizada para gibbsita (MILOT, 1970), formando a bauxita. Como essa transformação nunca é completa, algum conteúdo de caulinita pode permanecer. Num outro caso, o processo de degradação geoquímica da bauxita envolveria a transformação da gibbsita em caulinita (o inverso do caso anterior) através do processo de ressilicificação (KELLER \& CLARKE, 1984), também conhecido como caolinitização (DANGIC, 1985). Nesse processo, uma entrada de sílica e matéria orgânica pela vegetação provocaria a desestabilização da gibbsita e a caulinita seria neoformada (OLIVEIRA et al., 2013). Essa transformação se daria pelo desmembramento da couraça bauxítica e formação de um solo aluminoso.
A depender de um caso ou de outro, a bauxita pode ser mais ou menos enriquecida em caulinita. Em se tratando dos fragmentos analisados e da maneira como eles se inserem no perfil laterítico, os resultados de DRX e os estudos de gênese da bauxita na região (MATEUS et al., 2017) levam a crer que podem estar presentes os dois tipos de caulinita, sendo o segundo (caulinita formada dela degradação da gibbsita) mais comum nos fragmentos.

A resposta espectral obtida nos fragmentos de bauxita corrobora com a análise mineralógica. Foram observados nas curvas de reflectância pontos de inflexão (picos de absorção) dos principais minerais identificados por DRX, considerando a faixa espectral de 350 até $2500 \mathrm{~nm}$. Os principais pontos estão posicionados em 480, 940, 1441, 1910, 2205 e 2265 nm (Figura 4). Entre 480 e $940 \mathrm{~nm}$ tornam-se evidentes os minerais de composição ferruginosa, no caso das bauxitas em estudo, a goethita e hematita. É provável que tais pontos indiquem principalmente a presença da goethita, considerando ser ela a espécie mineral ferruginosa mais comum nas bauxitas brasileiras (CARVALHO, 1989; MELFI, 1997). Nos pontos 1441 e $1910 \mathrm{~nm}$ destaca-se a presença de feições de absorção associadas à presença da água. Conforme Hunt et al. (1971), em 1400 nm observam-se os principais efeitos da presença de $\mathrm{OH}^{-}$, sendo que em $1900 \mathrm{~nm}$ os efeitos ocorrem ainda mais pronunciados quando há argilominerais expansíveis (HUNT \& SALISBURG, 1971). Nas curvas obtidas, as inflexões em torno de 1400 foram mais evidentes que em $1900 \mathrm{~nm}$, considerando que os materiais investigados constituem produtos extremos de alteração e, por isso, não apresentam argilominerais $2: 1$. Ao contrário, as muitas feições de absorção no intervalo característico de $\mathrm{OH}^{-}$, e principalmente a presença da inflexão em 2265 $\mathrm{nm}$, reiteram a presença da gibbsita. Em se tratando da caulinita, conforme Clark et al. (1993), a presença de um dupleto em 2205 e aproximadamente $2185 \mathrm{~nm}$ caracteriza sua presença. Nas amostras coletadas, contudo, apenas uma sutil inflexão próxima de $2207 \mathrm{~nm}$ foi observada, sem que fosse possível reconhecer a presença de um dupleto. Diversos estudos demonstram que em razão de desordens estruturais esse dupleto pode não ser perfeitamente definido (DUCART et al., 2006; VELDE, 1992). Como a caulinita presente sugere ter sua origem relacionada à degradação da gibbsita, é provável que a baixa cristalinidade esteja influenciando sua detecção. Varajão et al (2001) e Oliveira et al. (2012) destacam o 
baixo grau de cristalinidade e menor tamanho de caulinitas provenientes da ressilicificação. Nesses termos, os estudos espectroscópicos por refletância contribuem, conforme observado por Vicente e Souza Filho (2011), para o estudo das transformações minerais em solos. $\mathrm{O}$ quartzo identificado nos difratograma não aparece nas curvas de reflectância porque sua faixa de absorção está no intervalo de 12000 a $14000 \mathrm{~nm}$, no Infravermelho Médio, após o limite de $2500 \mathrm{~nm}$ utilizado nessa pesquisa.

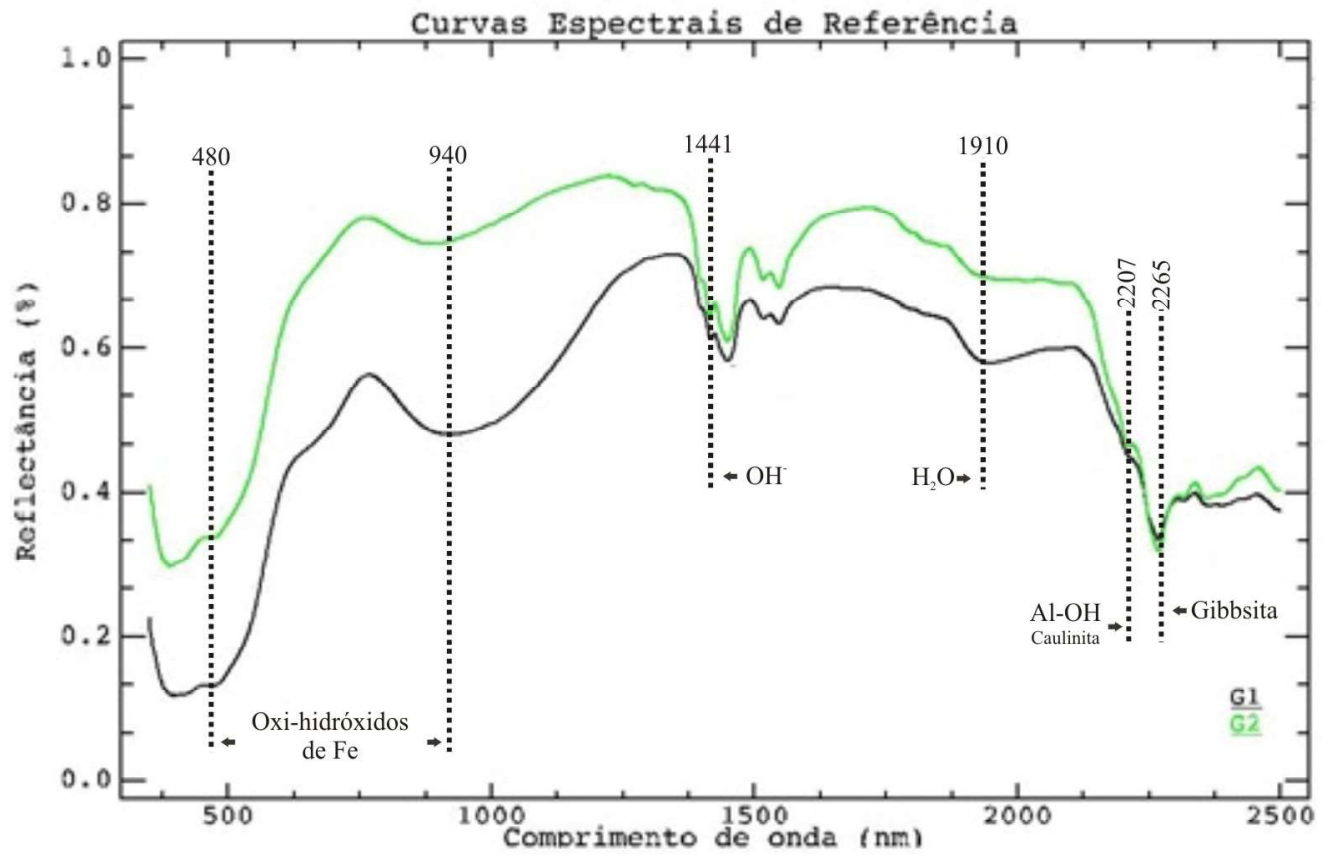

Figura 4 - Curvas espectrais representativas dos dois grupos (G1 e G2) de fragmentos de bauxita.

Os grupos individualizados mineralogicamente em decorrência da intensidade de detecção da gibbsita (G1 e G2) revelam-se coerentes nas curvas de reflectância. Embora muito semelhantes em termos dos pontos de inflexão observados (geometria da curva), eles se diferenciaram na intensidade da reflectância. G1 apresentou menor percentual de reflectância que G2, da ordem de 1 a $3 \%$ menor. Considerando o ponto da gibbsita $(2265 \mathrm{~nm}), \mathrm{G} 2$ apresentou picos de inflexão mais bem delineados. Nesses termos, a caracterização espectroscópica juntamente com a caracterização mineralógica sugere que os fragmentos presentes ao norte da área possuem maior grau de degradação (alterados para solo) que aqueles situados ao sul.

\subsection{Distribuição espacial da bauxita}

A identificação das possíveis ocorrências de bauxita, considerando a biblioteca espectral crida, variou conforme o ângulo analisado, tal como determina o classificador SAM. Dentre os testes realizados, o ângulo $0.20^{\circ}$ (radianos) foi aquele que apresentou os melhores resultados, registrando 178 pontos em que o comportamento espectral dos alvos na superfície se aproxima ao da bauxita (Figura 5). Acima de $0.20^{\circ}$ foram identificados muitos pontos, causando confusão na classificação. Abaixo desse valor, com o ângulo $0.19^{\circ}$, foram identificadas 18 possíveis ocorrências distribuídas aleatoriamente pela imagem e com pouca associação com as ocorrências já conhecidas. Embora quanto menor o ângulo, maior a acurácia do classificador SAM, a classificação com o ângulo 0.20 foi avaliada como sendo aquela que apresentou um numero satisfatório de possíveis ocorrências e foi a classificação que indicou pontos muito próximos das ocorrências já conhecidas em campo.

De posse dos pontos com indicação de ocorrência, e a partir de um roteiro minucioso de campo, foram realizadas visitas em praticamente todas as áreas indicadas pela classificação. Apenas alguns pontos localizados em área de difícil acesso ou em propriedades particulares sem autorização de entrada 
não foram aferidos. Para todos esses, áreas próximas contendo pontos indicados pela classificação tiveram seus resultados extrapolados. As conferências buscaram observar a presença da bauxita através de cortes de estradas, pela presença de fragmentos na superfície, por escavações feitas pela agricultura (como as covas para o plantio do café) e por meio de tradagens (trado manual).

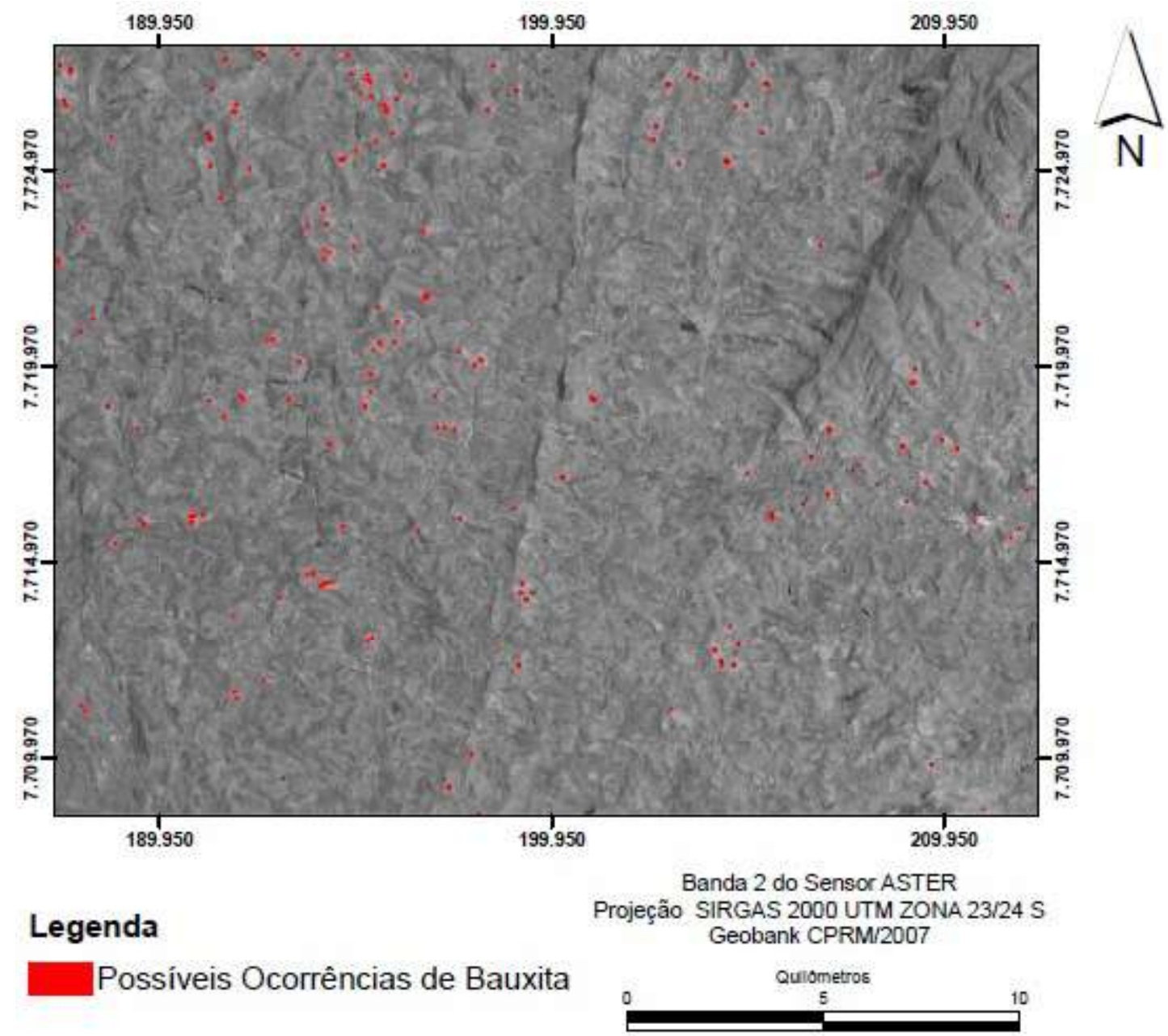

Figura 5 - Possiveis ocorrências de bauxita indicadas na classificação da imagem ASTER pelo classificador SAM com ângulo 0.020.

Do total de 178 possíveis ocorrências, 88 foram confirmadas, o equivalente a 49,5\%, que confere à classificação um limiar de razoável a bom (MENEZES \& ALMEIDA, 2011). As áreas com ocorrência confirmada foram indicadas em amarelo na Figura 6, e aquelas em que não houve a ocorrência foram identificadas em vermelho.

Nas ocorrências confirmadas, a bauxita é muito semelhante àquela nos depósitos já conhecidos e utilizados na obtenção da biblioteca espectral. Elas ocorrem na forma de fragmentos, centimétricos a decimétricos, rosados a esbranquiçados, sotopostos a uma camada friável de solo ou, por vezes, aflorando na superfície (Figuras 7a, 7b e 7c). Esses afloramentos, contudo, parecem indicar que houve a exposição dos fragmentos por interferência antrópica, já que estão associadas a encostas com escavações ou agricultura. Além disso, próximo a esses locais, seja por tradagem ou por cortes de estrada, a bauxita pode ser identificada abaixo da camada de solo. Por tais considerações, é possível supor que em escala regional a bauxita ocorre na forma de um perfil laterítico clássico, com a fáceis fragmentada sobreposta por cobertura pedológica com maior ( $2 \mathrm{~m})$ ou menor $(\sim 1 \mathrm{~m})$ espessura. Da mesma maneira, conforme observado na imagem e em campo, essas ocorrências são isoladas e, mesmo que se aglomerem nas porções sudeste, nordeste e noroeste da imagem, não há uma conexão entre elas que permita reconhecer, na atualidade, uma superfície bauxítica contínua. 
Silva F. S. et al.

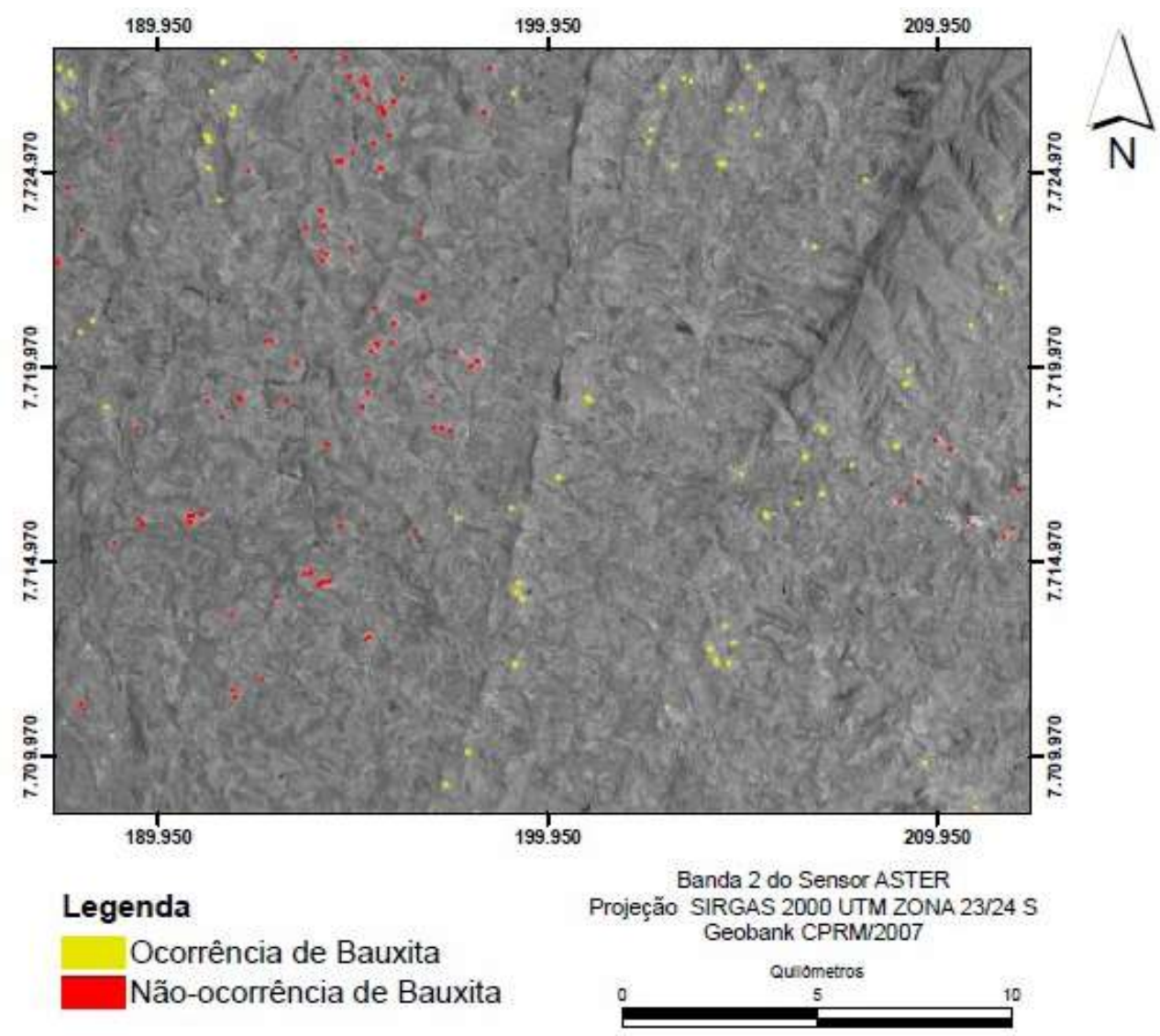

Figura 6 - Validação das possíveis ocorrências em campo com a indicação das ocorrências com bauxita, em amarelo, e das ocorrências sem bauxita, em vermelho.
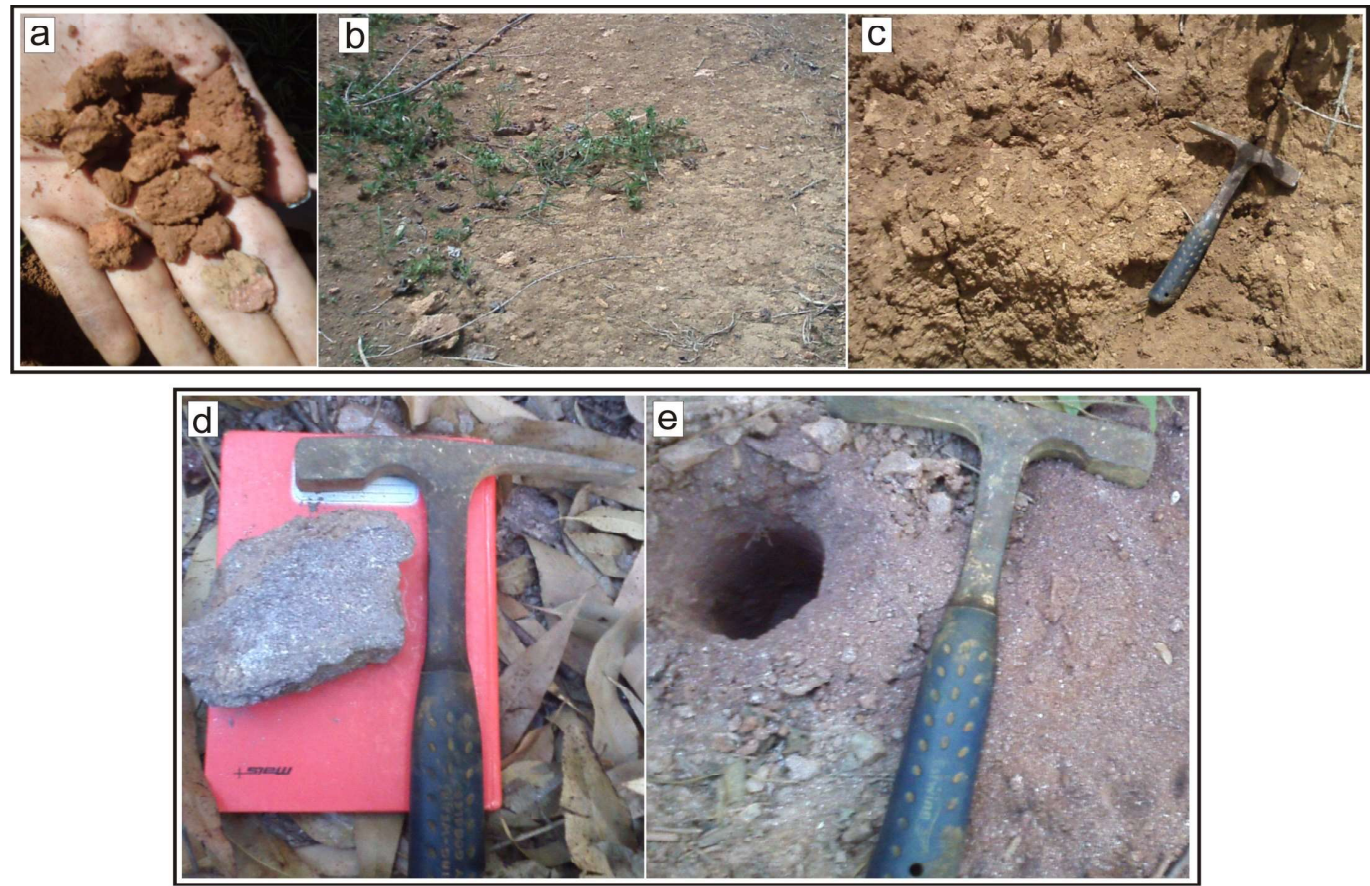

Figura 7 - Fotos representativas dos materiais nos pontos de conferência, sendo a = fragmentos de bauxita coletados no interior do perfil por tradagem; $b$ = fragmentos de bauxita dispersos na superfície em área de cultivo de café; $c$ = horizonte de bauxita fragmentada no interior de um perfil exposto por corte de estrada; $d$ = material saprolítico rico em mica e com pontuações esbranquiçadas de caulinita; $e$ = furo de trado em material saprolítico micáceo com fragmentos grandes de quartzo na superfície. 
Nas ocorrências não confirmadas há uma maior diversidade de materiais. Em muitos casos foi observada a presença de solos pouco profundos, constituídos na base por um saprolito muito friável (Figuras $7 \mathrm{~d}$ e $7 \mathrm{e}$ ). Pontuações esbranquiçadas de caulinita ocorrem intercaladas com paletas de muscovita, indicando serem produtos de sua alteração. Em alguns pontos, a muscovita ocorre com um material quartzo-arenoso. Outras ocorrências não confirmadas revelam a presença de um solo semelhante àquele encontrado sobre os fragmentos de bauxita, principalmente em termos de cor, mas sem conter, subsuperficialmente, tais fragmentos. Nestes casos, observa-se um saprolito rosado, caulinítico, com estruturas pseudomorfizadas típicas de bandamento gnaissico. As áreas em que a ocorrência da bauxita não foi verificada se distribuem ao longo de uma faixa sentido norte-sul na porção central da imagem e na extremidade leste da mesma. A gênese de solos a partir de rochas ricas em muscovita pode levar à formação de caulinita e gibbsita, aproximando essas coberturas da paragênese da bauxita, o que provavelmente levou a sua identificação pelo classificador.

\subsection{Contexto geológico-geomorfológico das ocorrências de bauxita}

As ocorrências de bauxita validadas em campo não representam grandes aglomerados, mais sim ocorrências pontuais de significativa presença. A superposição desses com alguns mapeamentos temáticos permitiram compreender em que contexto eles se inserem na paisagem (Figura 8).
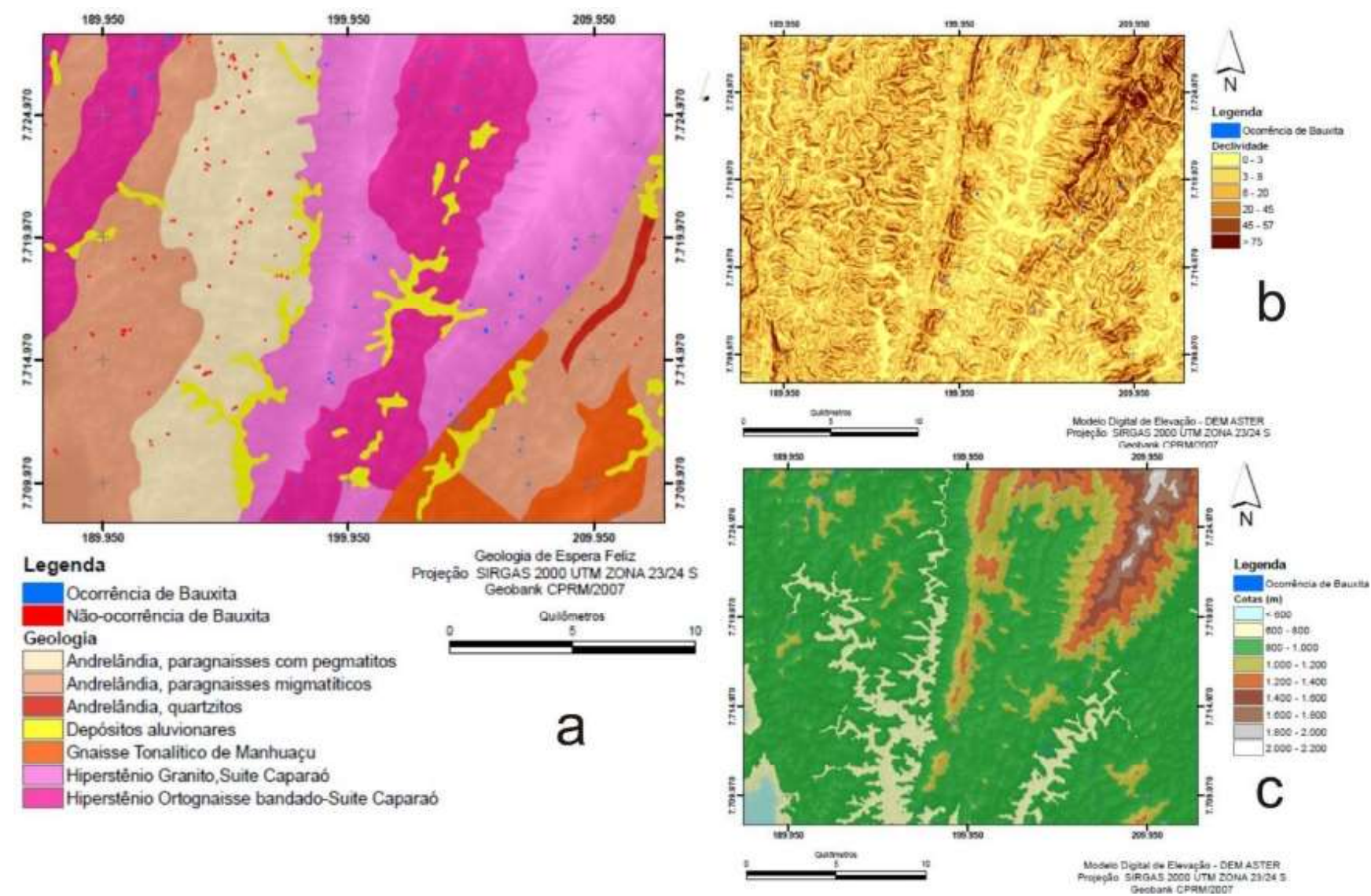

Figura 8 - Superposição das ocorrências de bauxita (em azul) no contexto litológico (a); de declividade (b) e hipsométrico (c).

Considerando o arcabouço litológico regional, a distribuição espacial das ocorrências de bauxita esteve fortemente associada às rochas da Suíte Caparaó (Figura 8 , Tabela 1). Do total de 88 ocorrências, $89,8 \%$ ocorre neste grupo, cujo litótipo predominante é um gnaisse ortoderivado, bandado, diorítico a granítico, de granulação média a fina de textura granoblástica com enclaves máficos centimétricos a métricos (NOVO et al., 2011). O potencial de tais rochas em gerar a bauxita é dado, conforme Soares (2013), por uma paragênese constituída principalmente por feldspato potássico e plagioclásio, além de outros minerais como ortopiro- 
xênio e hornblenda. O quartzo também está presente, porém como mineral residual da rocha a ser encontrado na bauxita, não sendo uma fonte de alumínio.

Além das rochas da Suíte Caparaó, algumas ocorrências podem estar relacionadas à presença do Gnaisse Tonalítico Manhuaçu, que foi descrito por Horn et al. (2007) como um ortognaisse granodiorítico, trondhjemítico a tonalítico, com porções de anfibólio-biotita-gnaisse, geralmente, orientado na direção N-S e de idade Neoproterozoica. O total de 5 pontos identificados na porção sudeste da área de estudo foram relacionados a essa rocha.

Em se tratando das ocorrências que não foram confirmadas como bauxita, destaca-se o Paragnaisse do Grupo Andrelândia, o que leva a crer que essas rochas não representaram, no contexto em que se insere a pesquisa, importantes formadoras de bauxita.

Tabela 1: Número de ocorrências em cada classe nos contextos apresentados na Figura 8.

\begin{tabular}{cccc}
\hline & Categoria & $\begin{array}{c}\text { Número } \\
\text { ocorrências }\end{array}$ & $\begin{array}{c}\text { \% no } \\
\text { total }\end{array}$ \\
\hline \multirow{2}{*}{ GEOLOGIA } & Ortognaisse Suíte Caparaó & 42 & 47,8 \\
& Granito Suíte Caparaó & 37 & 42,0 \\
& Gnaisse Tonalítico Manhuaçú & 4 & 4,5 \\
& Paragnaisses Grupo & 5 & 5,7 \\
\hline Andrelândia & $0-3$ & 6 & 7,3 \\
DECLIVIDADE & $3-8$ & 23 & 18,0 \\
(\%) & $8-20$ & 32 & 26,4 \\
& $20-45$ & 22 & 31,4 \\
& $45-75$ & 5 & 15,1 \\
& $75>$ & 0 & 1,8 \\
\hline \multirow{2}{*}{ ALTITUDE } & $<800$ & 0 & 0 \\
(m) & $800-1000$ & 54 & 61,4 \\
& $1000-1200$ & 27 & 30,6 \\
& $1200-1400$ & 6 & 6,9 \\
& $1400-1600$ & 1 & 1,1 \\
\hline
\end{tabular}

1 - Classes de declividade propostas pela EMBRAPA, 1979

Nos estudos regionais ou de mapeamento é comum o apontamento de que a gênese de bauxitas na região sudeste de Minas Gerais esteja relacionada tanto a: i) gnaisses e granulitos da Suíte Caparaó quanto aos ii) paragnaisses granatíferos do Grupo Andrelândia (VALENTON et al., 1991; ROMANO \& CASTAÑEDA, 2006; HORN et al., 2007; NOCE et al., 2007). Entretanto, quando se consideram os principais trabalhos de gênese em escala local (ROESER et al., 1984; LOPES, 1987; LOPES \& BRANQUINHO, 1985; VALENTON \& MELFI, 1988; BEISSNER, 1989; LOPES \& CARVALHO, 1989; BEISSNER et al., 1997; SOARES, 2014), a maioria destaca ocorrências associadas às rochas charno-enderbíticas em “i”, inclusive fazendo referência a anfibolitos que foram, posteriormente, reinterpretados como charnokitos milonitizados de cor esverdeada. Esse fato não exclui a possibilidade de formação de bauxitas a partir das rochas do Grupo Andrelândia, mas sinaliza que na região estudada a bauxita atualmente encontrada pode ser não participem da gênese da bauxita, mas é permissível considerar que o maior potencial encontrado está relacionado às rochas da Suíte Caparaó, ou que pelo menos na região de Espera Feliz tenham sido elas as principais rochas produtoras de bauxita.

Em se tratando dos aspectos geomorfológicos, as ocorrências de bauxita situam-se principalmente nos terços médio e superior das encostas, com algumas ocorrências também em topos de morros. Ao contrário do que foi observado por Lopes (1987) na região de Miraí, o relevo em Espera Feliz não se restringe a morros e colinas em formato de meia-laranjas, considerando que, por influência das estruturas do maciço do 
Caparaó, existem muitos espigões e cristas alongadas, ambos orientados de acordo com a foliação principal das rochas. Assim, a bauxita situa-se tanto na porção superior dos mares de morros quanto de alguns espigões. De qualquer maneira, não foi constatado na imagem e no campo a presença da bauxita nos fundos de vale e sopés das encostas. Nesses compartimentos predominam coberturas argilosas profundas. A declividade corrobora com a posição dos depósitos na vertente, considerando que quase todas as ocorrências estão situadas em relevos ondulados $(8-20 \%)$ ou forte ondulados (20-45\%). Em se tratando da altitude, $61,4 \%$ das ocorrências estão localizadas entre 800 e $1000 \mathrm{~m}, 30,6 \%$ entre 1200 e $1400 \mathrm{~m}, 6,9 \%$ entre 1200 e $1400 \mathrm{~m}$ e apenas uma ocorrência acima de $1400 \mathrm{~m}$.

\subsection{Inserção das ocorrências identificadas em Espera Feliz na escala regional}

A gênese de depósitos bauxíticos está relacionada à atuação de clima quente e úmido sobre rochas em áreas de relevo plano e bem drenado (TARDY, 1993). Tais rochas devem conter minerais cuja composição química envolve a presença de alumínio, considerando que será esse o elemento acumulado pela atuação do intemperismo intenso. As bauxitas encontradas na região de Espera Feliz se inserem nesse contexto e são, a exemplo das demais bauxitas conhecidas no território brasileiro (MELFI, 1997), produto dos processos de laterização.

As ocorrências identificadas na região de Espera Feliz através da classificação supervisionada encontram-se compartimentados na paisagem, à semelhança das ocorrências já conhecidas desde a década de 70 na região sudeste de Minas Gerais. Além disso, os resultados obtidos neste estudo demonstraram que a altitude, declividade e posição na vertente em que os depósitos se situam são semelhantes aos demais depósitos. Tais semelhanças confirmam que a região em estudo se insere, em escala regional, no cinturão aluminoso discutido em Valenton et al. (1991). Ainda assim, existem algumas pequenas diferenças nas ocorrências identificadas em Espera Feliz, destacando-se: i) as bauxitas ocorrem também em cotas superiores aos $1.000 \mathrm{~m}$, ao passo que na escala regional a maior parte dos depósitos situa-se entre 700 e 900m; ii) as ocorrências são, em termos espaciais, menores e mais isoladas que as ocorrências das regiões de Cataguases, Mirai, Descoberto, Itamarati de Minas, etc; e iii) a bauxitização figura ter sido mais intensa nas rochas da Suíte Caparaó que no Grupo Andrelândia.
De acordo com os estudos para a porção sudeste de Minas Gerais, a bauxita teria se originado a partir de uma superfície aplainada cretácica esculpida pela erosão, denominada Sul-Americana. A esculturação dessa superfície expôs rochas em escala regional, como os gnaisses do Complexo Juiz de Fora, no qual se inserem tanto a Suíte Caparaó quanto o Grupo Andrelândia. Sob um sistema bem irrigado, com precipitação volumosa, drenagem eficiente e relativa estabilidade tectônica, as rochas teriam sido alteradas para profundos mantos intempéricos, com a bauxitização em porções contínuas da paisagem, criando superfícies bauxitizadas. Posteriormente, essa superfície teria sido compartimentada através da erosão associada a períodos de reativação tectônica. Assim, a disposição dos depósitos no sentido NW-SO seria um produto conjunto da influência estrutural das rochas na sua gênese e do seu reposicionamento pela tectônica distensiva que afetou toda Plataforma Sul-Americana no Cenozóico.

No caso das bauxitas da região de Espera Feliz, sua distribuição concordante ao longo do terço superior das encostas e topos, bem como o caráter seccionado dos depósitos, leva a crer que também ocorreu a compartimentação de uma antiga superfície bauxítica. Contudo, o sensoriamento remoto mostrou que existem depósitos acima da cota de $1.000 \mathrm{~m}$. A concordância topográfica dos depósitos sempre foi um grande argumento para advogar a existência de uma paleosuperfície bauxitizada. O fato dos depósitos de Espera Feliz demonstrarem uma maior variação de cotas indica que a bauxitização pode ter ocorrido numa superfície que já continha irregularidades topográficas. Isso porque o maciço do Caparaó constitui uma antiforme cuja idade remonta ao Brasiliano, ao passo que a formação da superfície regional seria no final do Mesozóico e início do Cenozóico. A bauxitização, neste caso, é atribuída por diversos autores como sendo um evento de maior expressão no Eoceno e, posteriormente, no Mioceno (TARDY et al., 1991).

Os depósitos que hoje permanecem na paisagem de Espera Feliz seriam residuais, estando isolados pelo entalhe da drenagem, ou ainda degradados por processos de pedogênese. No primeiro caso, como dito, identifica-se o importante papel atribuído à reativação tectônica pós-Mesozóica, conforme destacado por Romano e Castañeda (2006). Soares (2013) enfatiza que a região de Espera Feliz apresenta nítidos indicadores da influência da neotectônica. Mesmo que alguns canais sigam a orientação preferencial da foliação 
(NNE), vários estão orientados conforme o padrão das fraturas (NW) responsáveis pelos principais lineamentos. Muitos canais formam corredeiras resultantes de deslocamentos verticais de blocos e muitas feições de meandros soerguidos são observadas nas vertentes. É provável que essa reativação tenha ocorrido durante o transcorrer do Cenozóico, quando todo o sudeste do Brasil foi tectonicamente reativado por pulsos (Saadi, 2005). Pesquisas em outros depósitos brasileiros destacam o importante papel que as reativações tectônicas no Oligoceno e Plioceno, sob clima seco, tiveram para a remobilização erosiva de depósitos. Zalán e Oliveira (2005) destacam que a máxima expressão da tectônica distensiva no sudeste brasileiro ocorreu entre 58-20 Ma, quando os horsts, formados paralelamente à linha da costa, foram erodidos, alimentando assim as bacias de Santos, Campos e do Espírito Santo.

A degradação geoquímica da bauxita é um importante mecanismo a considerar quando da necessidade de compreender porque os depósitos encontram-se em pontos isolados em Espera Feliz. Neste caso, nenhuma ocorrência foi verificada sem que houvesse a associação com uma cobertura pedológica. Essa cobertura tem sido apontada como resultado da degradação superficial da bauxita a partir de um processo conhecido como ressilicificação, induzido pela colonização vegetal em momentos de alternância para climas mais úmidos (VAN DER MAREL, 1960 apud VALENTON, 1974; TEWARI, 1963; ALEVA, 1965; VALENTON, 1974; BOCQUIER et al., 1982; BOULANGÉ \& BOCQUIER, 1983; BOULANGÉ, 1983; SÍGOLO \& BOULANGÉ, 1987; VARAJÃO et al., 2001; OLIVEIRA et al., 2013; MATEUS et al., 2017). Muitos depósitos isolados na paisagem podem ter sido totalmente, ou quase totalmente, degradados pela pedogênese, transformando-se em solos. Essa degradação influenciou, inclusive, na resposta espectral dos alvos, considerando que algumas bauxitas se encontram mineralogicamente mais ou menos transformadas.

\section{Conclusões}

A bauxita da região de Espera Feliz é predominantemente gibbsítica, com conteúdo variável de caulinita, quartzo e goethita. No caso da caulinita, esse conteúdo variável reflete os diferentes graus de degradação dos depósitos bauxíticos. O comportamento espectral da bauxita traduz, com clareza, sua mineralogia, sendo possível reconhecer, também pelas curvas espectrais, os diferentes graus de degradação nos quais os depósitos se encontram. Essa degradação é geoquímica e está associada à mudança das condições físico-químicas do ambiente, com importante papel da vegetação. Foram reconhecidos dois grupos de bauxita (G1 e G2), considerando as ocorrências utilizadas como amostras para a caracterização mineralógica e espectral.

Os resultados obtidos com auxílio de dados e técnicas de sensoriamento remoto neste estudo demonstram que as ocorrências de bauxita na região de Espera Feliz têm sua identificação dificultada pela maneira compartimentada como ocorrem na paisagem e pelo fato de estarem quase sempre encobertas por uma camada de solo. Não obstante, o sensoriamento remoto mostra-se como uma ferramenta de grande utilidade para a prospecção de ocorrências minerais, sobretudo quando essas apresentam aspectos que tornam complexo seu descobrimento por atividades estritamente de campo.

A espacialização das ocorrências de bauxita indica forte relação com rochas da Suíte Caparaó, o que revela um grande potencial das mesmas como produtoras de depósitos. A não confirmação da presença de bauxitas sobre os paragnaisses do Grupo Andrelândia não significa que tais rochas não sejam fonte geradoras de minério de alumínio. Os resultados até aqui obtidos permitem supor apenas que na região de Espera Feliz essas rochas não foram bauxitizadas, como ocorreu com os granulitos da Suita Caparaó.

Geomorfologicamente, a forma como as ocorrências estão localizadas na paisagem indica que a bauxita na região de Espera Feliz integra o cinturão aluminoso do sudeste de Minas Gerais, confirmando o modelo proposto por Lopes (1987). Em Espera Feliz, contudo, a presença de alguns depósitos em cotas altimétricas superiores pode ser um indicativo de que já no momento da formação da bauxita haviam irregularidades topográficas mais pronunciadas, tal como o maciço do Caparaó, que hoje constitui um conjunto de serras residuais alinhadas circundadas por um relevo colinoso.

A criação de uma biblioteca espectral com curvas de referência para tipos diferentes de bauxita é uma referência para futura identificação de outras áreas que contém esses materiais, o que a torna uma ferramenta importante e valiosa no mapeamento de novas ocorrências. 


\section{Agradecimentos}

Os autores agradecem à Fundação de Amparo a Pesquisa de Minas Gerais (FAPEMIG) pelo financiamento da pesquisa através do projeto Evolução do relevo associado a domínios de couraça bauxítica na Zona da Mata de Minas Gerais, ao Laboratório de Espectroscopia de Reflectância da Universidade Estadual de Campinas (UNICAMP) pela realização das análises e ao Conselho Nacional de Pesquisa (CAPES) pela concessão da bolsa de estudo do primeiro autor.

\section{Referências Bibliográficas}

ABRAMS M. The Advanced Spacebone Thermal Emission and Reflection Radiometer (ASTER), Data products for the high special resolution imager on NASA's EOS-AMI platform. International Journal of Remote Sensing, 21, p. 847-86, 2000.

ALEVA, G.J.J. The buried bauxite deposit of Onverdacht, Surinam, South America. Geologie en Mijnbouw, 44, p. 45$58,1965$.

BARDOSSY, G. Paleoenvironments of laterites and lateritic bauxites - effect of global tectonism on bauxite formation In: CHOWDNURY, M.K.R.; RAPHAKRISHMA, B.P; VALDYANADHAN, R.; BANERJEE, PK.; RANGANATHAN, K. (Eds.). Laterisation processes: international seminar. Rotterdam, Balkema, 1981, p. 287-294.

BARDOSSY, G., ALEVA, G.J.J. Lateritic bauxite. Amsterdam, Elsevier, 1990. 624 p.

BEISSNER, H. Geologie, Mineralogie und Geochemie der Bauxite auf praekambrischen Basement-gesteinen im Gebiet von Astolfo Dutra, SW-lich Cataguases, Minas Gerais, Brasilien. Doctor. Thesis - University of Hamburg, Hamburg, 1989. $228 \mathrm{p}$

BEISSNER, H.; CARVALHO, A.; LOPES, L.M.; VALETON, I. (1997). The Cataguases bauxite deposit. In: CARVALHO, A., BOULANGÉ, B., MELFI, A.J., LUCAS, Y. (Eds.), Brazilian Bauxites. $1^{\text {a }}$ ed., USP/FAPESP/ORSTOM, São Paulo, p. 195208.

BIGARELLA, J.J.; BECKER, R. D.; SANTOS, G. F. Estrutura e origem das paisagens tropicais e subtropicais. $2^{\mathrm{a}}$ ed., Editora UFSC, Florianópolis - SC, 2007. 425p.

BOCQUIER, G.; BOULANGÉ, B.; ILDEFONSE, P.; NAHON, D.; MULLER, D. Transfers, accumulation modes, mineralogical transformations and complexity of historical development profiles. II International Seminar on Laterization. Anais... São
Paulo, 1, 1982, p. 331-337.

BOULANGÉ, B. Les formations bauxitiques latkntiques de Côte d'Ivoire. Les facies, leur transformation, leur distribution et l'évolution du modelt. $\mathrm{PhD}$ Thesis, ORSTOM, Aix-en-Provence. 1984.

BOULANGÉ, B.; BOCQUIER, G. Le rôle du fer dans la formation des pisolites alumineux au sein des cuirasses bauxitiques latéritiques. Sciences et Géologie, 1, p. 29-36, 1983.

BRINDLEY, G.W.; BROWN, G. Crystal Structures of Clay Minerals and Their X-ray Identification. London, Mineralogical Society, 1980. 495p.

CARVALHO, A. As Bauxitas no Brasil. Tese de Livre Docência da Universidade de São Paulo, USP. São Paulo, 1989. 198 p.

CLARK, R.N.; SWAYZE, G.A.; GALLAGHER, A.; KING, T.V.V.; CALVIN, W.M.; The U.S. geological survey digital spectral library: Version 1: 0.2 to 3.0 um. USGS Open File Report 93-592. U.S. Geological Survey, 1993. 1340 p.

DANGIC A. Kaolinization of bauxite: a study in the Vlasenica Bauxite area, Yugoslavia. I. Alteration of matrix. Clay and Clay Minerals, 33(6), p. 517-524, 1985.

DUCART, D.F.; CRÓSTA, A.P.; SOUZA FILHO, C.R.; CONIGLIO, J. Alteration mineralogy at the Cerro La Mina epithermal prospect, Patagonia, Argentina: Field mapping, shortwave Infrared spectroscopy, and ASTER images. Economic Geology and the Bulletin of the Society of Economic Geologists, 101, p 981-996, 2006.

EMPRESA BRASILEIRA DE PESQUISAAGROPECUÁRIA EMBRAPA. Serviço Nacional de Levantamento e Conservação de Solos (Rio de Janeiro, RJ). Súmula 10. Reunião Técnica de Levantamento de Solos. Rio de Janeiro, 1979. 83p.

GOLDICH, S.S. A study in rock weathering. Journal of Geology, 46, p. 17-58, 1938.

HORN, A. H.; FARIA B.; GARDINI G. M.; VASCONCELLOS L.; OLIVEIRA M. R,. Mapa Geológico da Folha Espera Feliz SF.24-V-A-IV. Programa Levantamentos Geológicos Básicos Escala 1:100.000. Brasília, CPRM/UFMG, 2007.

HOSE, H.R. The genesis of bauxite: the ores of aluminum. 21ts Internacional Geological Congress. Proceedings, 16, 1960, p. 237-247.

HUNT, G. R.; SALISBURY, J. W. Visible and near infrared spectra of minerals and rocks: II Carbonate. Modern Geology, 2, p 23-30, 1971.

HUNT, G. R., SALISBURY, J. W., LENHOFF, C. J. Visible 
and near infrared spectra of minerals and rocks: III oxides and hydroxides. Modern Geology, 2, , p 195-295, 1971.

KELLER, W.D.; CLARKE, O.M.JR.. Resilification of bauxite at the Alabama Street Mine, Saline County, Arkansas, illustrated by scanning electron micrographis. Clays and Clay Minerals, 32, p. 139-146, 1984.

LOPES, L.M, A evolução mineralógica, micromorfológica e geoquímica da bauxita e materiais correlatos da região de Mirai. MScThesis, Instituto de Geociências, Universidade de São Paulo, São Paulo, 1987.120 p.

LOPES, L.M.; Carvalho, A. Gênese da bauxita de Mirai, MG. Revista Brasileira de Geociências, 19 (4), p. 462-469, 1989.

LOPES, R.F.; BRANQUINHO, J.A. (1988). Jazidas de bauxita da zona da Mata de Minas Gerais. In: SCHOBBENHAUS C., COELHO C.E.S. (eds.) Principais depósitos minerais do Brasil: metais básicos, não-ferrosos, ouro e alumínio. DNPM, Brasília, 3, p. 655-659.

MATEUS, A.C.C.; OLIVEIRA, F.S.; VARAJAO, A.F.D.C. ; SOARES, C. C. V. . Genesis of soils from bauxite in southeastern Brazil: resilification as a soil-forming process. Revista Brasileira de Ciência do Solo, 41, p. 1-18, 2017.

MATEUS, A. C. C. ; OLIVEIRA, F. S. ; VARAJAO, A. F. D. C. ; SOARES, C. C. V. ; SCHUNEMANN, A. L. Gênese de depressões fechadas em vertentes associadas à couraça aluminosa na porção sul da Serra do Caparaó, Minas Gerais/ Espirito Santo. Revista Brasileira de Geomorfologia, 17, p. 369-387, 2016.

MELFI, A.J. (1997). Brazilian bauxite deposits: a review. In: Carvalho, A., Boulangé, B., MELFI, A.J., LUCAS, Y. (Eds.), Brazilian Bauxites, $1^{a}$ ed., USP/FAPESP/ORSTOM, São Paulo, p. 3-22.

MENESES, P.R.; MADEIRA NETTO, J.S. Sensoriamento

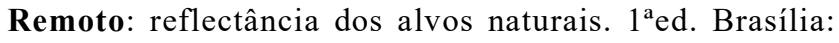
Universidade de Brasília (UnB), 2001. 262 p.

MENEZES, P.R.; ALMEIDA, T. Introdução ao Processamento digital de imagens de Sensoriamento Remoto. $1^{\mathrm{a}}$ ed. Brasília - DF: UNB/CNPQ, 2011. 200 p.

MILLOT, G. Geology of clays. Springer, New York, 1970. 425 p.

NAHON, D.; TARDY, Y. (1992). The Ferruginous Laterites. In.: BUTT, C.R.M.; ZEEGERS, H. (eds). Regolith, Exploration Geochemistry in Tropical and Subtropical Terrains. Elsevier Science Publishers, p. 41-54.

NOCE, C.M.; COSTA, A.G.; PIUZANA, D.; VIEIRA, V.S.;
CARVAlHO, C.M. Mapa Geológico da Folha Manhuaçu SF.23-X-B-III. Programa Levantamentos Geológicos Básicos Escala 1:100.000. Brasília, CPRM/UFMG, 2007.

NOVO, T.A.; NOCE, C.M.; PEDROSA-SOARES, A.C.P. Rochas granulíticas da Suíte Caparaó na região do Pico da Bandeira: embasamento oriental do Orógeno Araçuaí. Geonomos, 19 (2), p. 70-77, 2011.

OLIVEIRA, F.S.; VARAJÃO, A.F.D.C.; VARAJÃO, C.A.C.; BOULANGÉ, B. A comparison of properties of clay minerals in isalteritic and in degraded facies. Clay Minerals, 48, p. 697-711, 2013.

ROCHA, B.M.; SOUZA FILHO, C.R. Geração de bibliotecas espectrais de depósitos de bauxita brasileiros e exemplos de uso para a prospecção de minérios de alumínio por sensoriamento remoto orbital. Anais XVI Simpósio Brasileiro de Sensoriamento Remoto - SBSR, Foz do Iguaçu, Brasil, 2013.

RODRIGUES, K.R. Geoambientes e solos em ambientes altimontanos nos Parques do Itatiaia e Caparaó, MG. DScThesis, Departamento de Solos, Universidade Federal de Viçosa, Viçosa, 2011, 132 p.

ROESER, H.; ROESER, U.G.; GROSSI, A.W.R; FLORES, J.C.C. Contribuição à origem das jazidas de bauxita de Cataguases, Minas Gerais. In: Congresso Brasileiro de Geologia, 33. Anais. Rio de Janeiro, SBG, 8, 1984, p. 853-65.

ROMANO, A.W.; CASTAÑEDA, C.A. Tectônica distensiva pós-mesozóica no condicionamento dos depósitos de bauxita da Zona da Mata Mineira. Geonomos 14 (1, 2, p. 1-5, 2006.

RUHE, R.V. Geomorphology. Boston, Houghton Mifflin, 1975. $255 \mathrm{p}$.

SAADI, A.; BEZERRA, F.H.R.; COSTA, R.D.; IGREJA, H.L.S.; FRANZINELLI, E. (2005). Neotectônica da Plataforma Brasileira. In: SOUZA C.R.G.; SUGUIO, K.; OLIVEIRA A.M.S.; OLIVEIRA, P.E. (eds.) Quaternário do Brasil. Ribeirão Preto, Holos, p 211-234.

SANTOS. T.V. Fluxos de calor na superfície e evapotranspiração diária em áreas agrícolas e de vegetação nativa na bacia do Jacuí por meio de imagens orbitais. Dissertação de mestrado em Sensoriamento Remoto, Universidade Federal do Rio Grande do Sul. Porto Alegre, 2009, 96p.

SIGOLO, J.B.; BOULANGÉ, B. Caracterização das fácies de alteração de uma topo-seqüência no maciço alcalino de Passa Quatro, MG. Revista Brasileira de Geociências, 17, p. 269$275,1987$.

SOARES, C.C.V. Gênese e evolução mineralógica, 
micromorfológica e geoquímica da bauxita de Espera Feliz,

MG. Dissertação de mestrado em Evolução Crustal e Recursos Naturais, Universidade Federal de Ouro Preto. Ouro Preto, 2013, 104 p.

SOUZA FILHO, C.R., CRÓSTA, A.P. Número Temático da Revista Brasileira de Geociências: Geotecnologias Aplicadas à Geologia, 33, São Paulo, 2003, 227p.

TARDY, Y. Pétrologie des laterites et des sols tropicaux. Paris, Masson, 1993. 416 p.

TARDY, Y.; KOBILSEK, B.; PAQUET, H. Mineralogial composition and geographical distribution of African and Brazilian periatlantic laterites. The influence of continental drift and tropical paleoclimates during the past 150 million years and implications for India and Australia. J. African Earth Sci., 12 (1/2), p. 283-295, 1991.

TEWARI G. P., Occurrence of kaolinite in association with iron-pan. Nature, 198, p. 10-19, 1963.

UNIVERSIDADE FEDERAL DE VIÇOSA- UFV. Mapa de solos do Estado de Minas Gerais. Fundação Estadual do Meio Ambiente, 2010. 49p.

VALENTON, I. Bauxites. Elsevier, Development in Soil Science, 1, 1972. $213 \mathrm{p}$.

VALENTON, I. Resilification at the top of the foreland bauxite in
Surinam and Guyana. Mineralium Deposita, 9, p. 169-173, 1974.

VALETON, I.; MELFI, A.J. Distribution pattern of bauxites in the Cataguases area (SE Brazil), in relation to Lower Tertiary paleogeography and younger tectonics. Science Géologique Bulletin, 41 (1), p. 85-98, 1988.

VARAJÃO A.F.D.C.; GILKES R.J.; HART R.D., The relationships between kaolinite crystal properties and the origin of materials for a brazilian kaolin deposit. Clay and Clay Minerals, 49, p. 44-59, 2001.

VARAJÃO, C.C.; MENEZES, P.R. Detecção de depósitos bauxiticos em coberturas Lateriticas através de imagens TM, Sinclinal do Gandarela, Quadrilátero Ferrifero, MG. VI Simposio Brasileiro De Sensoriamento Remoto, 6., 1988, Natal. Anais. Natal, Rio Grande Do Norte, Brasil, p. 275-280p.

VELDE, B. Introduction to clay minerals. London: Chapman e Hall, 1992. 198 p.

VICENTE, L.E.; SOUZA FILHO, C.R. Identification of mineral components in tropical soils using reflectance spectroscopy and advanced spaceborne thermal emission and reflection radiometer (ASTER) data. Remote Sensing of Environment, 115, p. 18241836, 2011.

ZALÁN, P. V.; OLIVEIRA, J.A.B. Origem e evolução estrutural do sistema de riftes cenozóicos do sudeste do Brasil. Boletim de Geociências da Petrobras. 13(2), p. 269-300, 2005. 